\title{
Are We Winning the War on Cancer?
}

\author{
By Ted Okon, MBA, and Lee Schwartzberg, MD, FACP
}

This year, we mark the 40-year anniversary of the National Cancer Act. The law expanded the scope and funding of the National Cancer Institute, among other initiatives, in what has become known as the "war on cancer." Looking back over the years, it is indisputable that we have made dramatic inroads in fighting cancer. A just-released report by the Centers for Disease Control and Prevention estimates that the number of survivors of cancer in the United States has increased from 3 million in 1971 to 11.7 million in $2007 .{ }^{1}$ Yet cancer still claims the lives of more than .5 million Americans each year and ranks close behind cardiovascular disease as the leading cause of death. ${ }^{2}$ In this article, we offer our perspectives on how the war on cancer is going from the clinical and policy frontlines and postulate on what the future holds.

\section{Battles Have Been Won With Some Impressive Results}

There is little debate that cancer care delivery in the United States has evolved dramatically in the past 40 years and has produced impressive results. Aided by therapeutic and delivery advances, fellowship-trained oncologists have set up private practices across the country that have moved cancer care from the inpatient, academic center complex to the outpatient, community setting. Today, four of five Americans battling cancer are treated close to home in independent practices or those affiliated with hospitals. ${ }^{3}$ The community model of cancer care has provided high-quality, affordable, and accessible treatment to patients with cancer.

Oncologists have been aided by significant advances in how they diagnose, treat, and manage cancer. For instance, the death rate from breast cancer decreased by approximately $2 \%$ per year between 1990 and 2006.4 The multifactorial reasons for this decrease include widespread use of screening tests—such as mammography, which has increased early detection—as well as improvement in treatment in the adjuvant and metastatic setting. We can now realistically talk about certain metastatic cancers as chronic diseases given that patients often live many years with good quality of life.

These encouraging results extend to the entire population. The increase in cancer mortality rates has been reversed, and 5-year survival rates for the United States demonstrate the strength of our cancer care delivery model. For example, American women have a $63 \%$ chance of living for at least 5 years after a cancer diagnosis compared with $56 \%$ for European women; American men have a 5-year survival rate of $66 \%$ compared with a rate of only $47 \%$ for European men. ${ }^{5}$

\section{Public Policy May Stand in the Way of Victory}

Unfortunately, public policy has changed the reimbursement model for Medicare, which accounts for approximately half of the payments for cancer care and threatens the advancements made to date. The intent of the Medicare Modernization Act of 2003 was to better balance the payment for cancer drugs and medical services. However, the law left shortfalls in the reimbursement of services, which have been exacerbated by additional payment cuts made by the Centers for Medicare \& Medicaid Services. A study that was based on actual practice costs and completed by the policy firm Avalere Health estimated that Medicare reimbursed only $57 \%$ of the cost of delivering cancer care in $2009 .{ }^{6}$

Because Medicare is such a large payer, it exerts inordinate influence over the reimbursement system, with an escalating number of private payers following Medicare rates. It is increasingly difficult for private practices to operate under conditions in which Medicare reimbursement prevails. As a result, noncompensated but critical services — such as nutrition and counseling — are being abandoned as a result of lack of funding. Compounding the shortfalls in the reimbursement of cancer care is Congress' inability to fix the overall Medicare payment system on the basis of the sustainable growth rate (SGR). After a series of short-term patches during 2010, Congress managed to pass a bill averting a severe cut in Medicare payments until January 1, 2012. If Congress does not act to patch or fix the flawed SGR-based payment system, a 29.5\% cut in Medicare rates will become effective.

Further clouding the environment for oncology is the Patient Protection and Affordable Care Act (ACA), the health care reform bill that passed into law in 2010. The law includes some positives for cancer care such as the eliminations of annual and lifetime insurance caps, coverage for preventive services like colonoscopy and mammography, and prohibition of exclusion of the routine costs of cancer care for patients in clinical trials by private insurers. However, there are several provisions in the law that are disconcerting to oncology practices. Chief among these is the creation of the Independent Payment Advisory Board, which is charged with simply cutting Medicare spending to providers when certain targets are exceeded—a type of SGR on steroids.

Because of reimbursement cuts from both federal and private payers and the general economic climate, oncology practices are being forced to operate in an environment of tremendous uncertainty. Any type of business planning beyond the current year is meaningless and makes running the business side of an oncology practice difficult at best. A practice impact tracking report shows that 199 cancer treatment sites have closed during the past 3 years, and an additional 369 oncology practices are under financial pressure. ${ }^{7}$ With the unpredictability of revenue streams and adverse market conditions, momentum is building for alternative affiliations. Many oncology practices are entering into arrangements with hospitals that include outright purchase, professional service agreements, and comanagement opportunities. It is possible that such arrangements may influence patient access to care in the future. 
The greatest uncertainty facing oncologists and all physicians is the extent to which ACA will be implemented. Republicans in Congress have launched a legislative assault to defund and repeal provisions in the law, and the Supreme Court is likely to decide whether the cornerstone of reform - the mandate that will require all Americans to have insurance or pay a penalty-is constitutional. Regardless of the final fate of ACA, it is clear that this landmark legislation has already profoundly influenced the thinking of practices, hospitals, and payers, given the emphasis on coordinating care and promoting quality and costeffective initiatives in medicine.

\section{Oncologists' Drive to Innovate Gives Hope}

Just as oncologists created and evolved the world's best cancer care delivery system, this culture shift has inspired many to further innovation despite the challenges placed in their way. Consultants in Medical Oncology and Hematology in Drexel Hill, Pennsylvania, which is led by John Sprandio, has reengineered its approach to become the first community oncology practice in the country to earn the highest, level III recognition from the National Committee for Quality Assurance under its Patient-Centered Medical Home Program. ${ }^{8}$ At the time of diagnosis, physicians in this practice assume primary responsibility for the patient's cancer treatment as well as for the coordination of all the patients' other medical care, extending through the development and implementation of a survivorship plan. At the heart of this patient-centered medical home model are specific definitions of quality and value in the delivery of cancer care. The promise of health care reform-namely, enhancing quality and controlling costs - is becoming a reality.

Other community oncology practices are pursuing novel innovative reimbursement initiatives with payers in attempts to forge win-win relationships that preserve and foster the delivery of quality cancer care. Several practices from around the country are working with UnitedHealthCare on a program built around agreed-upon treatment guidelines and episodes of care for 19 different cancers and disease states on the basis of stage of cancer. In this scenario, the drugs become a pass-through item and are not the drivers of operating margin. Risk is shared by both the practice and the managed-care organization. By comparing actual with planned use within and across practices, this program has the potential to continually provide guidance to move toward best treatments for specific diseases and stages.

Other practices are looking to increase participation in networks that clinically integrate care by using prespecified care plans that are based on national practice guidelines. In oncology, there is a strong evidence base that focuses on clinical trialtested regimens, which are constantly updated by such authorities as the National Comprehensive Cancer Network and the American Society of Clinical Oncology. These guidelines offer the opportunity for oncologists, who are among the most prevalent adopters of electronic health records in medicine, to continually monitor compliance with process in treating patients according to prespecified plans and to scrutinize patient outcome. Community oncologists are thus well poised to be leaders in accountable care organizations as these are formed under hospital, payer, or physician leadership.

This fundamental change in the way cancer care is organized and delivered comes against a background of groundbreaking discovery into the basic biology of cancer. The understanding that a finite number of critical oncogenes and pathways drive cancer growth and metastasis has reached a level at which rational therapeutics can be designed against cancer tissue-specific targets, enhancing efficacy and reducing toxicity. Already, early fruits of this labor have been recognized with US Food and Drug Administration approval of multiple agents against previously difficult-to-treat cancers such as renal cell carcinoma. Recognition that every tumor type is itself comprised of multiple subsets that are driven by different mutations with each possibly requiring a different approach will actually add to the complexity of ensuring appropriate care as the decision tree and system support needs will be large. Improvement in health informatics that are user friendly and easy to implement in the clinic hold the promise to aid in care delivery and allow monitoring of quality cancer treatment in the emerging age of personalized cancer care.

\section{Public Policy May Decide the Outcome of the War}

There is no doubt that we have made positive inroads in terms of winning the war on cancer. The tools are in place and increasing in both sophistication and precision for additional progress toward making cancer a true chronic disease if not ultimately to find cures. We question, however, whether public policy will erect insurmountable barriers that ultimately make winning the war difficult if not impossible. With an increasing demand for cancer care that is driven by the demographics of an aging population that is far outpacing the supply of oncologists and the ongoing transformation of the reimbursement system, the challenges facing oncology are formidable. The first stage of the war involved scientific advancements, ingenuity, and entrepreneurial spirit in developing the cancer care delivery system that is the model for the world. The next stage will require the collaboration of oncology providers and payers to explore innovative ways of preserving and developing the model even further to foster quality and cost-effective cancer care.

Accepted for publication on April 4, 2011.

Authors' Disclosures of Potential Conflicts of Interest

The authors indicated no potential conflicts of interest.

\author{
Author Contributions \\ Conception and design: Ted Okon, Lee Schwartzberg \\ Manuscript writing: Ted Okon, Lee Schwartzberg \\ Final approval of manuscript: Ted Okon, Lee Schwartzberg
}

Ted Okon, MBA, is Executive Director, Community Oncology Alliance. Lee Schwartzberg, MD, FACP, is Medical Director, West Clinic. 


\section{References}

1. Centers for Disease Control and Prevention (CDC): Cancer Survivors - United States, 2007. MMWR 60:269-272, 2011

2. American Cancer Society: Cancer Facts \& Fiqures, 2010. http://www.cancer. org/acs/groups/content/@nho/documents/document/acspc-024113.pdf

3. National Cancer Institute: NCI Community Cancer Centers Program (NCCCP): Pilot Program Summary - January 2007

4. Jemal A, Siegel R, Xu J, et al: Cancer statistics, 2010. CA Cancer J Clin 60:277-300, 2010

5. Verdecchia A, Francisci S, Brenner H, et al: Recent cancer survival in Europe: A 2000-2002 period analysis of EUROCARE-4 data. Lancet Oncol 8:784-796, 2007
6. Avalere Health: Providing high quality care in community oncology practices: An assessment of infusion services and their associated costs. htto:/ www.communityoncology.org/docs/Avalere-COA-Components-of-Care-StudyFinal-Report.pdf

7. Community Oncology Alliance: Community oncology cancer care practice impact report: Documented impact on community oncology practices. htto://wmw.

communitvoncologv.org/UserFiles/files/e6c14902-aebb-4368-8d8f-b14234f95161 COA\%20Community\%200ncology\%20Practice\%20Impact\%20Report\%20723-10.pdf

8. Sprandio JD: Oncology patient-centered medical home and accountable cancer care. Community Oncol 7:565-572, 2010 